\title{
Forest cover loss in Paraguay and perception of ecosystem services: A case study of the Upper Parana Forest
}

\author{
Emmanuel Da Ponte ${ }^{\mathrm{a}, *}$, Claudia Kuenzer ${ }^{\mathrm{b}}$, Amanda Parker ${ }^{\mathrm{c}}$, Oscar Rodas ${ }^{\mathrm{d}}$, Natascha Oppelt ${ }^{\mathrm{a}}$, \\ Martina Fleckenstein ${ }^{c}$ \\ ${ }^{a}$ Kiel University, Department for Geography, Remote Sensing E Environmental Modelling, Kiel, Germany \\ ${ }^{\mathrm{b}}$ German Remote Sensing Data Center, DFD of the Earth Observation Center, EOC, of the German Aerospace Center, DLR, Oberpfaffenhofen, Germany \\ ${ }^{\mathrm{c}}$ World Wildlife Fund, Berlin, Germany \\ ${ }^{\mathrm{d}}$ World Wildlife Fund, Asuncion, Paraguay
}

\section{A R T I C L E I N F O}

\section{Article history:}

Received 4 October 2016

Received in revised form 7 March 2017

Accepted 8 March 2017

\section{Keywords:}

Paraguay

Atlantic forest

Forest cover loss

Ecosystem services

Household survey

Perception

\begin{abstract}
A B S T R A C T
The Upper Parana Atlantic Forest (BAAPA) in Paraguay is one of the most threatened tropical forests in the world. Relentless agricultural encroachment has left less than $10 \%$ of its original cover intact. Many strategies and programs have been initiated, such as Payment for Ecosystem Services (PES) schemes, to halt forest cover loss. While the approach of ecosystem services (ES) has been continuously applied by policy makers, it has not been perceived strongly by the direct users of the forest. This study provides a comprehensive understanding on how landowners in the BAAPA perceive and benefits from ES derived from the forest and examines the influence of farmers on forest conservation. The results were obtained from an extensive household survey performed in the BAAPA region. An understanding of the high ecological value of the forest is common to all farmers. A strong dependency on forest-related products was observed for small and medium landowners whereas large-scale farmers considered the forest's main value to be mostly recreational and cultural. PES appears to be well accepted by forest owners, but it must receive stronger promotion. Understanding the importance of ecosystem services is a valuable contribution toward to conserving natural resources.
\end{abstract}

(c) 2017 Elsevier B.V. All rights reserved.

\section{Introduction}

Tropical forest cover has fluctuated greatly over recent decades. The continued encroachment of agricultural crops, cattle ranching, and illegal logging has endangered their connectivity, by converting the last remnants of tropical forest into isolated patches. (FAO, 2007). Between the 2000 and 2005 South America has lost over 22 million ha of forest, accounting for almost 60\% (22, 3 million ha per year) of total forest cover loss in the world (FAO, 2007, 2010, 2015a). Even though deforestation rates have decreased compared with previous years (WWF, 2013), they remain a crucial concern. Recent studies conducted on a global scale identified Paraguay as one of the countries in Latin America with the highest deforestation rates worldwide (Hansen et al., 2010, 2013). The rapid deforestation rate has resulted in the loss of $90 \%$ of the forest cover in the eastern region of the country, where the Upper Parana Forest is situated (Fleytas, 2007). The Upper Parana Forest includes 15 ecoregions that encompass a total area of $471,204 \mathrm{~km}^{2}$. It

\footnotetext{
* Corresponding author.

E-mail address: daponte@geographie.uni (E. Da Ponte).
}

extends from the Atlantic coast of Brazil, passing through the eastern region of Paraguay and reaching the northwestern side of Argentina (Bitetti et al., 2003). The eco-region has a high level of biodiversity and includes numerous endemic species that are not found anywhere else in the world (Mayers, 1988; Mittermeier et al., 1999; Myers et al., 2000; Olson and Dinerstein, 2002). Before the 1940s, much of the original Upper Parana Atlantic Forest in Paraguay (BAAPA) remained intact covering approximately 55\% of the eastern region of the country (nearly $9,000,000$ ha), but currently less than $10 \%$ of its original cover remains (Fleytas, 2007; Hutchison and Aquino, 2011; Da Ponte et al., 2015). One of the major reasons attributed to deforestation activities in the BAAPA, besides the continuous expansion of mechanized agriculture (particularly soybean production), is the lack of profitable opportunities for forest owners. There are few economical alternatives besides timber and charcoal production. Consequently, the high levels of income obtained from agricultural exports have encouraged the expansion of large-scale crop production, tempting small-scale farmers to lease their land to large companies that are interested solely in single crops such as soy bean and maize. There are several strategies, conventions, and monitoring 
programs that were implemented to halt forest loss. One of the most promising alternatives is the Payments for Ecosystem Services (PES) program, also known as payments for environmental services (WWF, 2015b). The PES compensates farmers with incentives for managing their land to provide any type of environmental service (WWF, 2015b). The described concept has been implemented by the Paraguayan Government under the name of "Valuation and Retribution of Ecosystem Service Law 3001/2006" (PES $3001 / 2006)$. The regulation establishes a mechanism in which forests owners receive compensation for preserving their forest reserves and other natural environments, rather than converting their land into other land uses. The Paraguay forest regulation (422/73) requires that properties larger than 20 ha must preserve the natural forest on 25\% of its land area. The PES 3001/06 law permits landowners with environmental liabilities to purchase environmental certificates from those who exceed the 25\% minimum forest cover required for a renewal period of 5 years (Kernan et al., 2010). The Ministry of Environment in Paraguay (SEAM) has established a fixed cost for environmental certificates based on the eco-region from which the certificate has been issued, and this cost varies between \$154 USD (Chaco Meadows) and \$885 USD (Central Littoral) per ha.

According to SEAM, of the 20 registered properties, seven are located in the BAAPA, and only one of these forest owners had made a successful transaction for the sale of one certificate for 15 ha $(\$ 570$ USD per ha) (SEAM, 2016). Ecosystem services (ES) was defined by the Millennium Ecosystem Assessment (2005) as "the benefits that people obtain from ecosystems" (Carpenter, 2005). The ES definition includes provisioning services such as timber and firewood; regulating services such as erosion and climate regulation; supporting services such as nutrient cycling and soil formation; and cultural services such as recreational and spiritual (Fig. 1). ES can be differentiated based on their use value: direct use values (for forest, e.g., the provision of wood and medicine); indirect use values (for forest, e.g., purification of water strands and tourism); option values (for forest, e.g., genetic resources); and existential values (for forest, e.g., educational and spiritual) (Hein et al., 2006).

While the ES approach has increasingly been included within environmental regulations as a way to support biodiversity conservation and sustainable management of ecosystems (e.g., National law 7575/1996 PES in Costa Rica, PES 3001/2006 law in Paraguay, and the 30215 law in Peru) (Bennet and Henninger, 2009; Kernan et al., 2010; Alegría, 2012; Casado-Arzuaga et al., 2013; WWF, 2015a), the comprehension of its concept remains limited (Lamarque et al., 2011). The small number of studies that considered the local peoples' perception of ES prevents effective imple- mentation of proper ES-based conservation initiatives (Sodhi et al., 2009). Awareness about ES differs among sites, based on cultural characteristics, geographic location, life experiences, and use of natural resources (Daily, 1997; Costanza, 2000; Kuenzer and Tuan, 2013; Grima et al., 2016). Thus, case studies are considered to be especially important for capturing these local differences (Lamarque et al., 2011). The goal of this study is to provide a comprehensive understanding of the perception of forest ecosystems services in the BAAPA; the type of landowners who inhabit in the area and their educational background; how the usage of the services derived from the forest differs among different farm types (small, medium, and large); the degree of interest towards to susceptibility to conservation/restoration programs; and the current challenges and threats facing the BAAPA. The outcomes obtained in this study provide useful information when contemplating the importance of social involvement in land-use planning.

\section{Study area}

The Upper Parana Atlantic Forest is located in the eastern region of Paraguay (Fig. 2(b)). It encompasses portions of ten departments and 141 districts in the region, accounting for a total area of $86,000 \mathrm{~km}^{2}$ (DGEEC, 2002). The BAAPA contains almost $50 \%$ (over 3,167 million inhabitants) of the country's population, who are distributed between 65\% (around 2065 million inhabitants) in urban settlements and 35\% (over 1102 million inhabitants) in rural areas (DGEEC, 2002). Cities with a larger population in the ecoregion are situated in the East (Ciudad Del Este) and South (Encarnación), whereas the North is less occupied. According to the Landscan Project (Oak Ridge National Laboratory, 2013), in 2010, the average population density outside urban areas varied between 5 and 100 residents per $\mathrm{km}^{2}$ (Oak Ridge National Laboratory, 2013). The climate of the Atlantic Forest is typical for sub-humid tropical zones with frequent rainfall that varies from 1300 to $1800 \mathrm{~mm}$ per year. The annual average temperature is $22^{\circ} \mathrm{C}$ with a relative humidity of $80 \%$. However, the temperature fluctuates considerably between seasons. During winter months (May-August), temperatures can drastically decrease to $0^{\circ} \mathrm{C}$, whereas in summer, (December-March) they can rise to $42{ }^{\circ} \mathrm{C}$. The main economic activities in the region are cattle ranching, cotton and corn, sugar cane, mate tea (Ilex paraguariensis), and soy bean production. Paraguay produces approximately nine millions tons of soy beans per year, accounting for three percent of worldwide production (Markey, 2014). Currently, over 3 million ha (90\% of the country's production) of soy bean plantations are located within the boundaries of the BAAPA region (MAG, 2008). However,

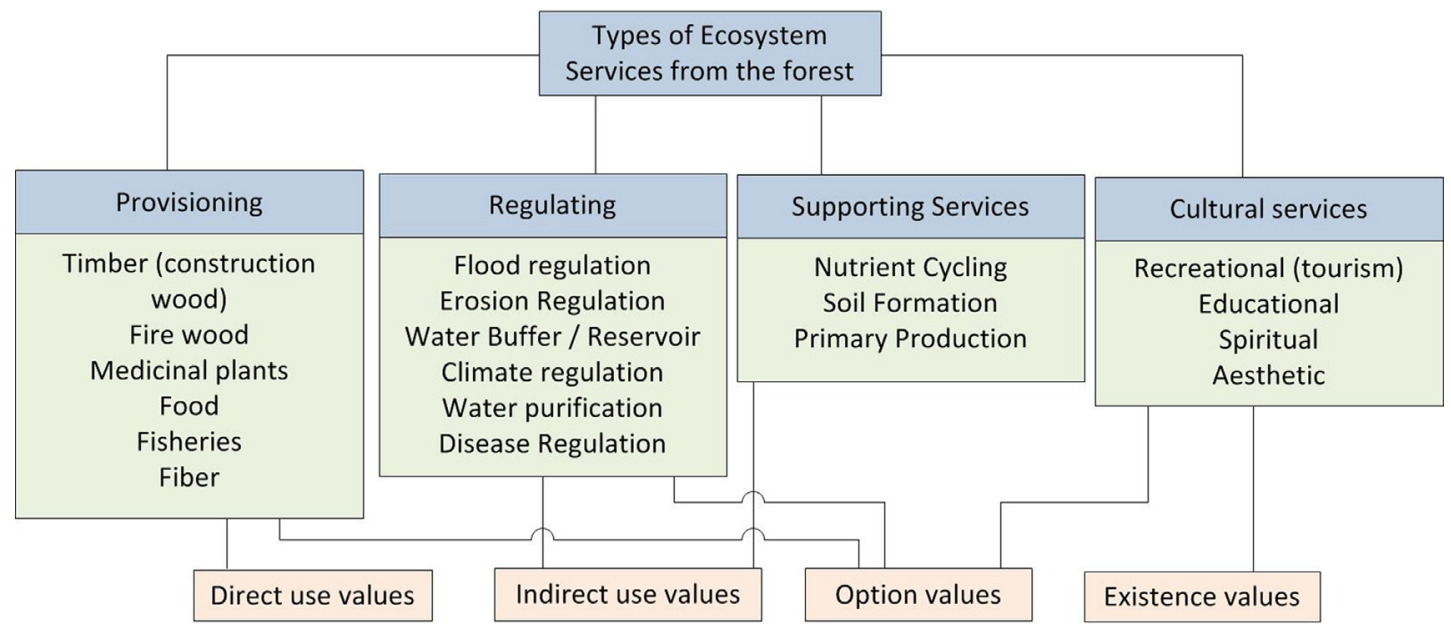

Fig. 1. Ecosystem service and ecosystem service value derived from the forest (Adapted from MEA, 20005). 


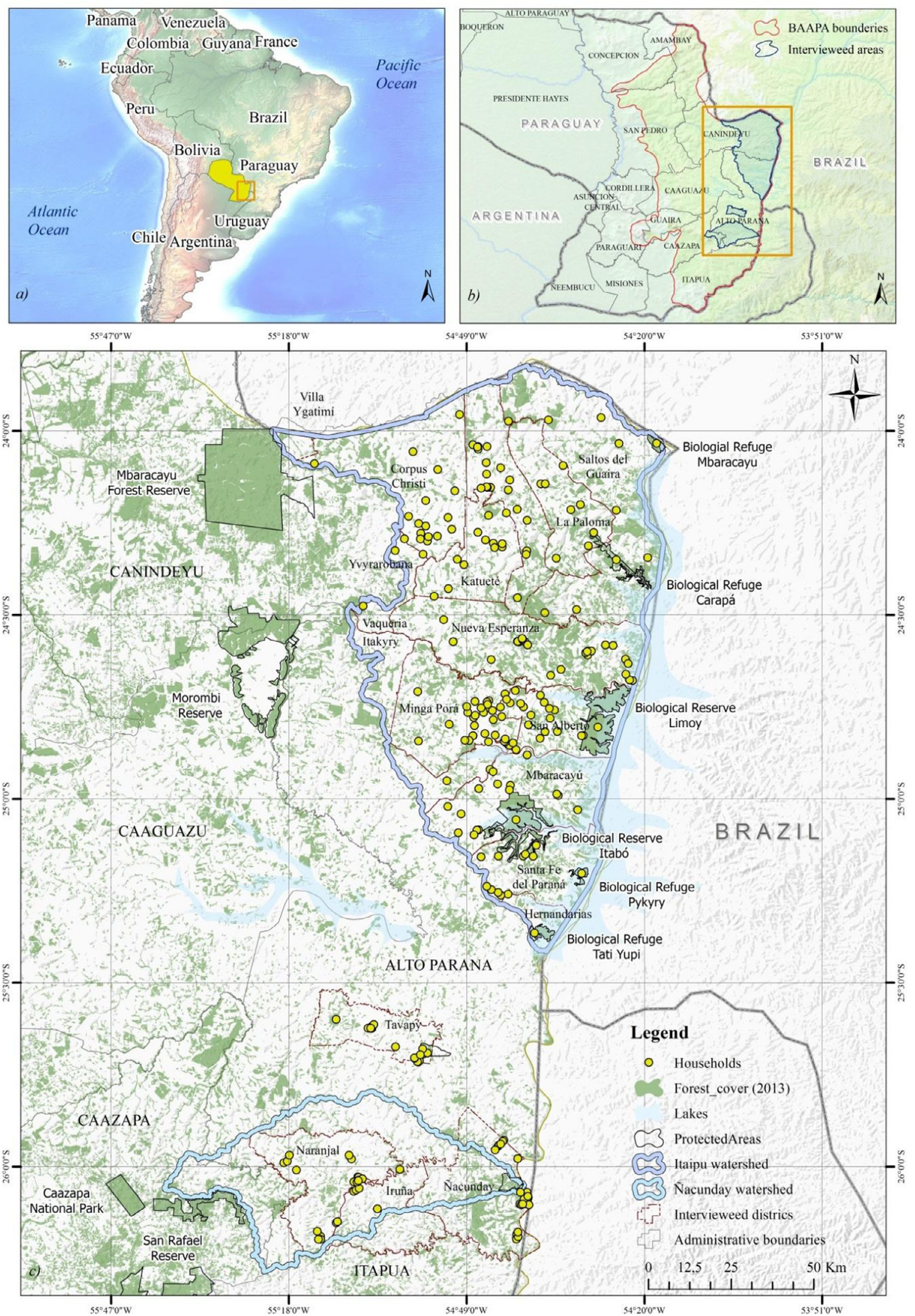

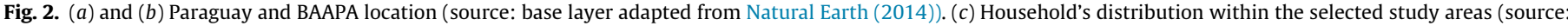
base forest layer adapted from Da Ponte et al. (2016)). 
projections from the United States Department of Agriculture (USDA) estimate that soy production could grow over the next 5-10 years, to cover up to 4 million ha (Markey, 2014).

The ecology of the region includes semi-deciduous forest, which predominates in the landscape of the BAAPA (Stern and Kernan, 2011). Forest types in the area can broadly be classified as follows: high forest, with large trees up to $35 \mathrm{~m}$ tall that are of high timber value (Handroanthus heptaphyllus, Cordia trichotoma); low forest, with open savannas and flooded areas that are mainly used for charcoal and firewood (Peltophorum dubium, Luehea divaricata); riverside forest, along the riverside and flood plains with only a small commercial value (Ruprechtia laxifolia, Cupania vernalis); and savanna forest, which are small areas that are highly important for research purposes (Gochnatia polymorpha, Helietta apiculata) (Stern and Kernan, 2011).

In the 1950s, much of the original BAAPA forest cover remained intact. At that time, forest cover still accounted for 8,931,000 ha (55\% of the eastern region of the country). Since the late 1960s, deforestation rates have increased steadily. According to Huang et al. (2007, 2009), direct causes of deforestation were associated with the long-held perception of the forest as nonproductive land, the frequent unsustainable use of forest resources by settlers, and the expansion of the agricultural frontier. Between 1973 and 2000, Paraguay lost almost two thirds of its Atlantic Forest, reaching deforestation rates of $2000 \mathrm{~km}^{2}$ per year (Huang et al., 2007). Although, the government intended to encourage reforestation programs in the late 1990's as a mean to limit ecological damage (incentives to forestation and reforestation law 536/96), it did not achieve good results (UN-REDD, 2010). The lack of economic resources along with unclear regulations decreased the trust of local landowners towards the government, stating that in most of the cases "no financial support was given" (UN-REDD, 2010).
In 2004, the Paraguayan government passed the "Zero Deforestation Law" (2524/04), which forbids any conversion of forest lands in the eastern region of the country (Hutchison and Aquino, 2011; Kernan et al., 2010). According to the World Wildlife Fund (WWF) (2013), deforestation rates in the Atlantic forest decreased by $90 \%$ from 2002 to 2009 , from 110,000 ha per year to 8,000 ha per year. Following this initiative, in 2003 , the government created the PES law 3001/06 (Kernan et al., 2010).

The BAAPA forest provides various goods and services for the local people and industries who settle in the region. According to the Ministry of Agriculture of Paraguay (MAG), charcoal and firewood constitute the main source of energy for more than $51 \%$ of rural livelihoods and for $87 \%$ of the industrial sector in the area (MAG, 2008). Over 50,000 ha of fuel wood is harvested every year for the purposes of energy production (MAG, 2008). The BAAPA comprises suitable environmental conditions for forest farming such as Ilex paraguayensis (mate tea crops) or Ananas comosus. Additionally, the BAAPA has been frequently used as a source of food and medicinal goods. The forest supports soil erosion control, and is also used as a resting area. However, inhabitants with less economic resources tend to generate income via direct use of natural resources (frequently resulting in extensive wood harvesting) rather than sustainably generating a long-term income. The unsustainable extraction of forest resources has led to ever-increasing forest defragmentation and forest degradation.

\section{Materials and methods}

A socioeconomic household survey was conducted in the BAAPA region in January 2016. Two hundred seventy-seven interviews were conducted with the designated head of each household (Fig. 3). Two field technicians from WWF Paraguay, two forestry
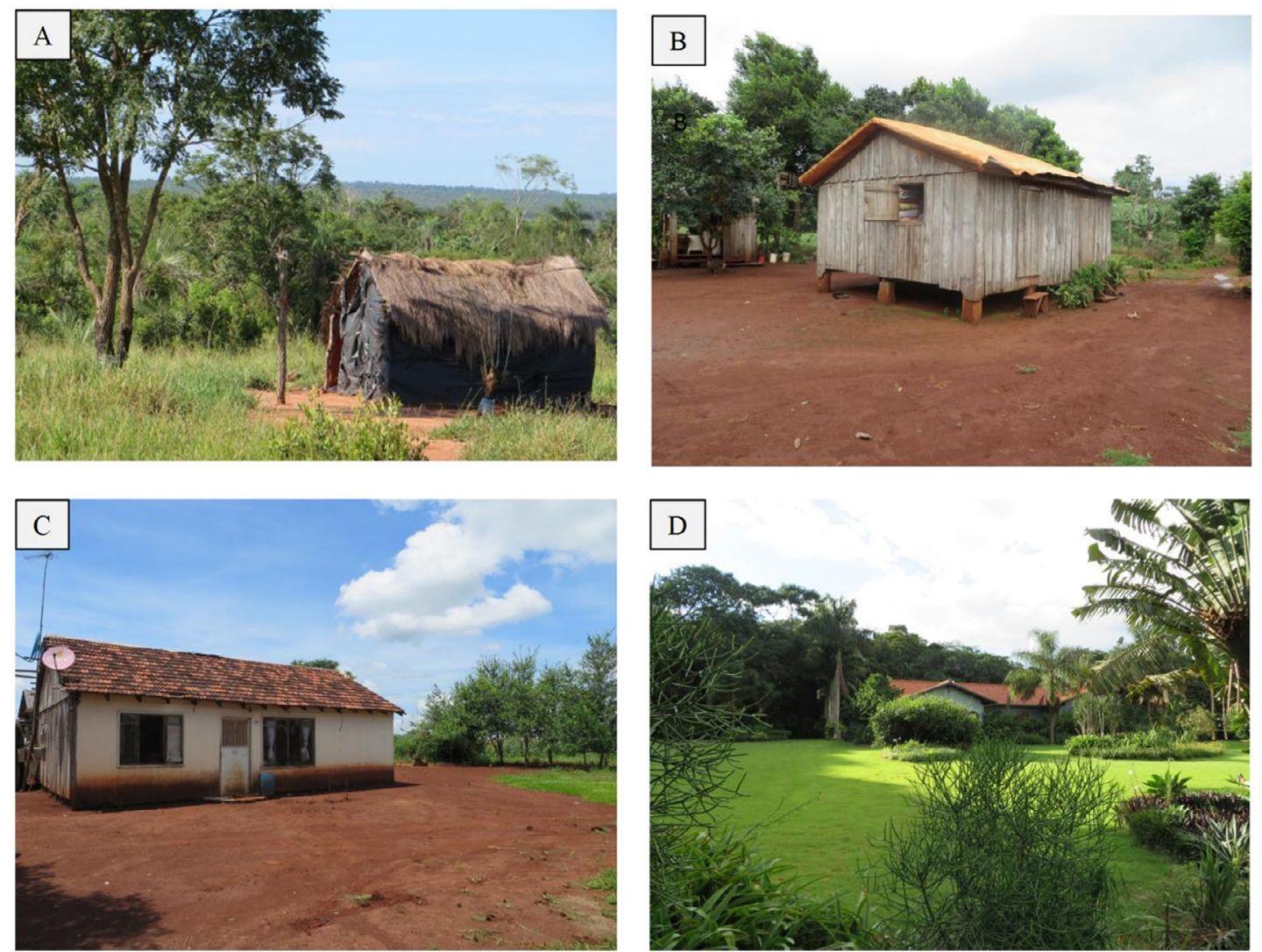

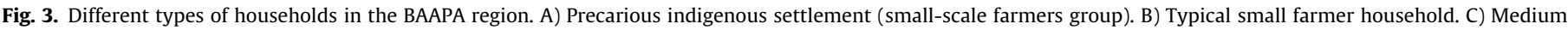
farmer household. D) Large farmer household (soy bean producer). 
students from the National University of Asuncion (U.N.A), and other field assistants (e.g. school teachers and local leaders) helped with performing the interviews. To ensure that the interviews were undertaken in an identical manner, interviewers were first trained and agreed on the questioner standards before the field survey started. Because of the BAAPA region's large size, three sample areas were selected to conduct the survey: the ITAIPU watershed $(1,000,000$ ha) in the North, and the Ñacunday watershed (250,000 ha) and Tavapy district (43,600 ha) in the South (see Fig. 2(c)). The selected regions have been working closely with the United Nations (UN) program on Reducing Emissions from Deforestation and Forest Degradation (REDD+), PES, and restoration initiatives because of their status as priority areas for conservation (WWF, 2015a). They were considered to be pilot project areas for carbon stock and environmental credit programs (WWF, 2015a). For example, in 2012, WWF Paraguay started a project (Paraguay Land Use (PARLU)) under the framework of REDD+ program. PARLU aimed to integrate human activities and forest conservation by developing alternative livelihoods that could lower the pressure of deforestation and forest degradation. The total sampling area comprised two departments (Alto Parana and Canindeyú), and 19 districts inhabited by over 279,300 people who live in 42,490 individual households. To include all types of forest owners in the region, six protected areas within the ITAIPU watershed (see Fig. 2(c)) were included in the survey, and the leader responsible for each forest reserve was interviewed.

The sampling approach was based on a "convenience sampling methodology" by taking into account factors such as the willingness of potential respondents, extreme weather events (such as severe flooding, intense rain storms, and blocked roads) restricting the access to farmers, and time limitations resulting from the size of the selected areas. The survey was carried out over a 6-week period. Each interview was conducted in Portuguese, Spanish, and Guarani (indigenous language) with each taking about two hours to complete. The survey consisted of a 13-page questionnaire that was designed in English and translated into Spanish and partially into Guaraní. The sample size was calculated by applying the formula of Yamane (1967) after Israel (1992) and Kuenzer and Tuan (2013), as shown in Eq. (1):

$\mathrm{n}=\mathrm{N} /\left[1+\mathrm{N}(e)^{2}\right]$

where $\mathrm{n}$ is the samples needed; $\mathrm{N}$ is the sample population; and $e$ is the sampling error (7\%).

According to Eq. (1), a total of 204 samples are necessary to achieve representative results. The present household survey yielded responses of a total of 277 households, and can thus be considered as representative of the region.

The survey comprises 117 questions overall, of which 41 were multiple choice questions allowing for a single answer only; 66 were multiple choice questions allowing for multiple answers; and 10 were open-ended questions. When analyzing the collected data, landowners were differentiated according to the size of their farm, as follows: small-scale farmers were landowners with $<20$ ha; medium-scale farmers were landowners with 20-50 ha; and large-scale farmers were landowners $>50$ ha (Fig. 3 ). This stratification was based on the same standards applied by the Ministry of Agricultural of Paraguay in its rural censuses (PNUD, 2010). In regards to protected areas, there were not enough reserves to consider them as a separate category, so protected areas were placed into the large-scale farm group considering the size of the reserve (all of them larger than 50 ha). The collected data was analyzed using the Statistical Package for the Social Sciences (SPSS) software. Correlation exploration applying frequency and contingency tables was used to visualize relevant patterns and to present the findings as plots and charts, which are shown in the following sections.

Thus, we developed a questionnaire regarding the state of the BAAPA and local expertise from experienced working professionals (non-governmental organizations (NGOs)) in the region based on the above information. The survey also focuses on some broad properties of the rural population, such as job, income, education level, land surface, and forest type. These factors also serve as an indicator of the importance to the forest by local farmers (e.g. respondents with a low income level would be more likely to depend on forest resources for subsistence). The survey is divided into several sections that focus on different aspects. Section 1 relates to the general properties of the household such as educational background, land ownership, land size, and net income. Section 2 is orientated to assess the perception of landowners towards the natural forest by including a variety of question such as: how do you define the forest? Do you have any knowledge of which forest species are on your land? Do you think that natural forests serve a particular function? Where did you learn about these functions? Do you think that forests have an economic (monetary) value? How important is the forest for your livelihood? Are there any negative characteristics of the forest that you would like to mention? Overall, Section 2 is dedicated to the value that farmers place on the forest. In Section 3, the survey evaluates the uses of the forest by farmers, focusing on the benefits and products obtained from the forest along with their related economic value, and how much the forest contributes to the overall annual income of the household. Section 4 is oriented towards conservation and protection programs, assessing the participants' understanding of such programs and their willingness to participate in the programs. Section 5 is dedicated to the participants' characterization of their forest land, such as forest regulations, opinions, and experiences with law enforcement, and expected future trends.

\section{Results}

\subsection{Demography}

Interviews for this study were conducted with the designated head of the household. Approximately $87 \%$ of the respondents were males, predominantly between 40 and 55 years of age. Most interviewees had a primary or secondary school education (Fig. 4).

The proportion of respondents with primary education slightly decreased as farm size increased, varying from $67 \%$ (for small-scale farmers) to $40 \%$ (for large-scale farmers). Secondary school, however, differs from the previous trend where most respondents were medium scale-farmers (29\%) and large-scale farmers (24\%). The largest proportion of farmers with a lower education level was found in the small-scale farmers group, which accounted for $17 \%$ of interviewees without a school education. Conversely, a higher education (university level) is more common among large-scale farmers, who comprised $28 \%$ of the respondents in this category. Household ownership varies between Colons (Brazilians) and Paraguayans. Fig. 5 shows a gradient trend: Paraguayan ownership tends to decrease with larger farm size. About $88 \%$ of the smallscale farmers interviewed were Paraguayans, whereas $87 \%$ of large-scale farmers were Colons. Household size varied between one and 11 members, with an average of three to five family members. When asked about their main occupation, almost $94 \%$ considered themselves to be farmers, whereas a smaller percentage (6\%) held jobs in governmental institutions or owned grocery stores in addition to farming. The interviewed farmers focused mainly on soy bean production (large-scale farms), cattle (medium-scale and small-scale farms), mate tea (small-scale farms), and subsistence agriculture (small-scale farms). The average land area owned 


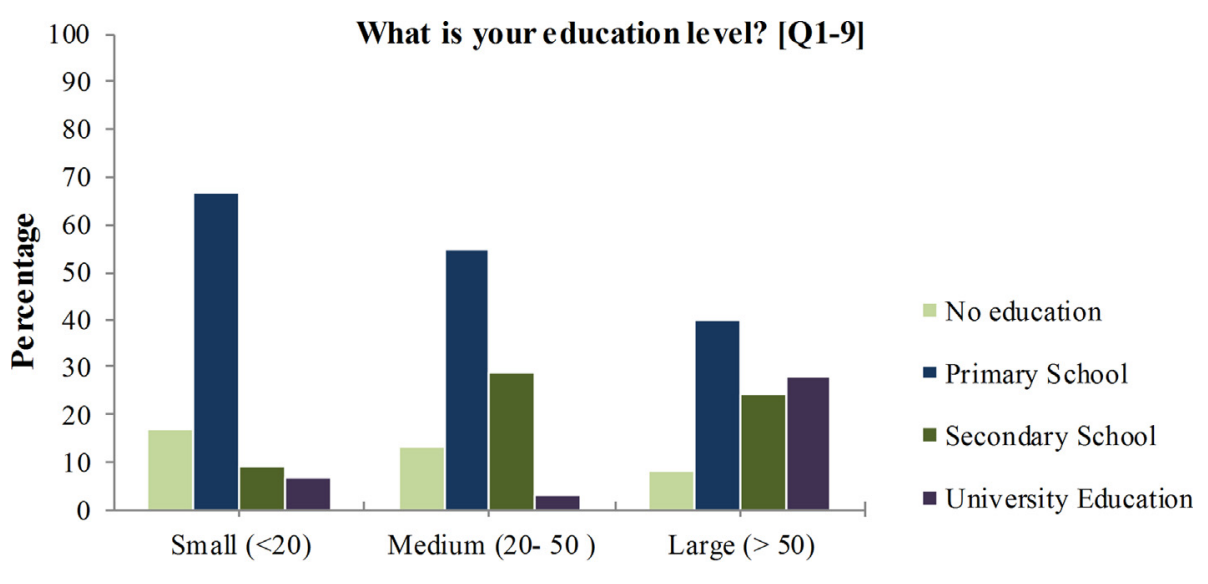

Farm size

Fig. 4. Education level according to farm size of respondents [Q1-9].

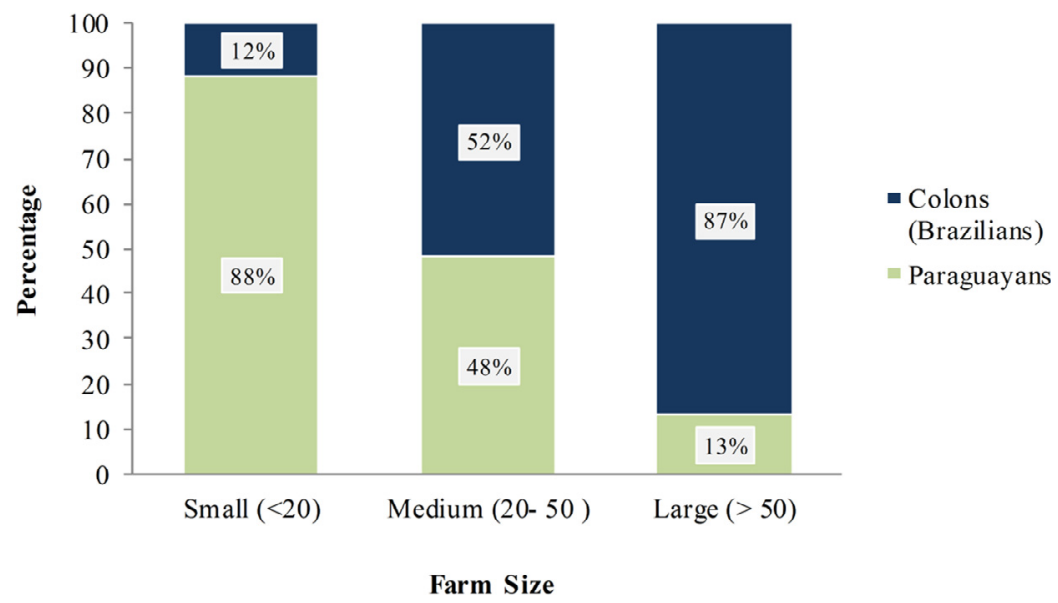

Fig. 5. Household ownership according to farm size of respondents [Q1-6].

by the farmer groups is 750 ha for large-scale farmers, 27 ha for medium-scale farmers and 9 ha for small-scale farmers.

Interviewees were asked for their average annual salary, not taking into consideration the income source. Answers were given in Guaranies (PGY) and converted into USD. For the purpose of this study, five different categories were established, ranging from less than $\$ 1,000$ USD to over $\$ 50,000$ USD. Results in Fig. 6 show that land ownership is broadly proportional to annual salary. In general, over $34 \%$ of households have an income below the annual rural wage per capita (around \$6,500 USD estimated by the Direction of Census and Statistics from Paraguay (DGEEC, 2002)), when considering that household sizes average three to five members in the region. Small-scale farmers had the lowest income, with $79 \%$ of the respondents in the range of $\$ 250-\$ 5,000$ USD per year.

Moderate to high incomes were reported in the medium-scale farmers' group with incomes ranging from $\$ 11,000$ USD- $\$ 81,000$ USD for $81 \%$ of the respondents. Large-scale landowners had the highest annual income, accounting for $95 \%$ of the interviewees and with profits above $\$ 50,000$ USD. They reached this level of income principally from large-scale mechanized farming (mostly soy bean production).

\subsection{Understanding of natural forest perception in households}

In general, there is no clear definition of a forest. Most interviewees used either a single or multiple functions of a forest to char- acterize it. Approximately $64 \%$ of the respondents referred to the forest as a natural area that needs to be conserved. The majority of the respondents (95\%) understood the importance of the forest for water cleansing, biodiversity conservation, erosion control, cultural heritage, and recreational purposes, and to provide natural resources (such as medicinal plants, firewood, and construction wood). The forest functions described here were not recognized by less than $4 \%$. When asked about how they learned these functions, almost $43 \%$ of the respondents stated "from personal experience" and 38\% indicated "from teachers or professors". With regards to the economic value of the forest, almost 95\% agreed that the forest had an economic value, but stated that it did not contribute actively to their net income (according to $71 \%$ of the respondents). When asked about the negative characteristics of a forest, $30 \%$ of the respondents pointed out certain conflicts caused by the presence of natural areas. Fig. 7 shows that trespassing, either because of illegal logging or hunting, is a major threat reported by all farmers' groups; the larger the farm, the higher the rate of trespassing

\subsection{General uses of forest in households and forest related income}

Overall, $79 \%$ of landowners stated that they frequently benefited from the forest, and $92 \%$ considered the forest to be important for their livelihoods. A more in-depth analysis (Fig. 8) revealed that $97 \%$ of small landowners indicated that they were highly depen- 


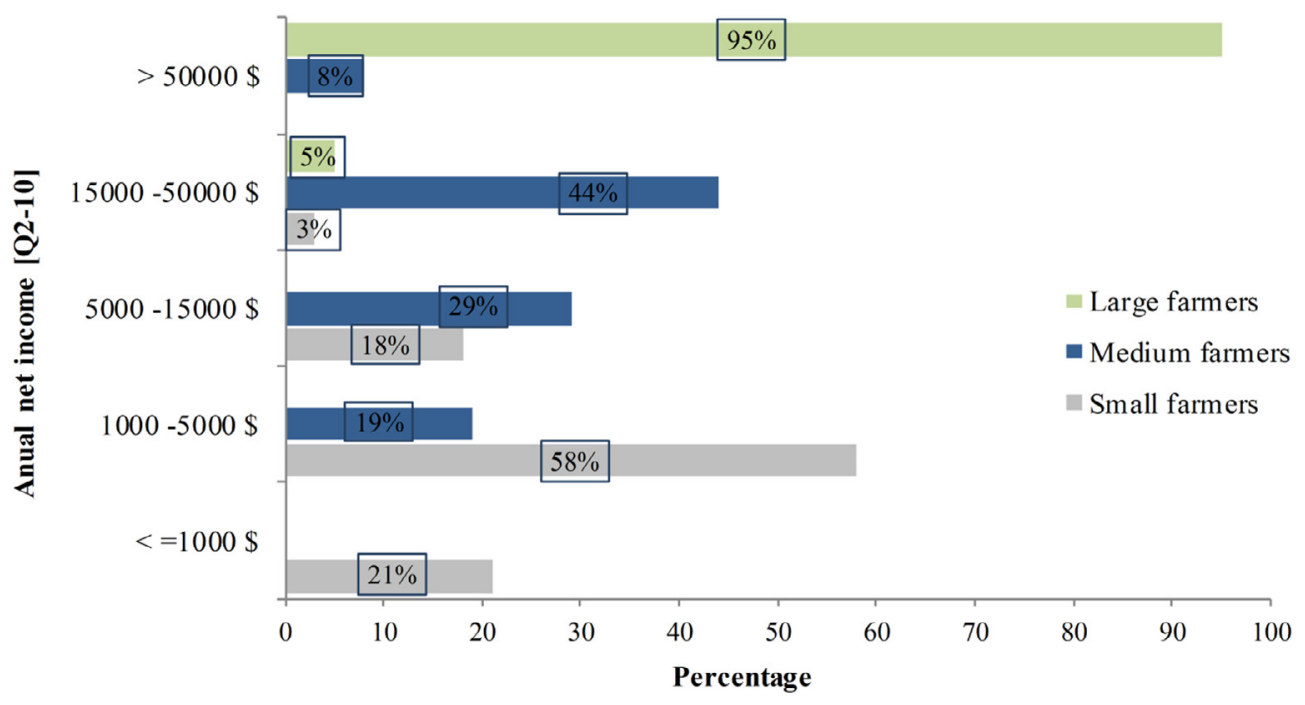

Fig. 6. Income distribution according to farm size of respondents.

Are any negative aspects of the forest that you would like to mention? [Q3-9]
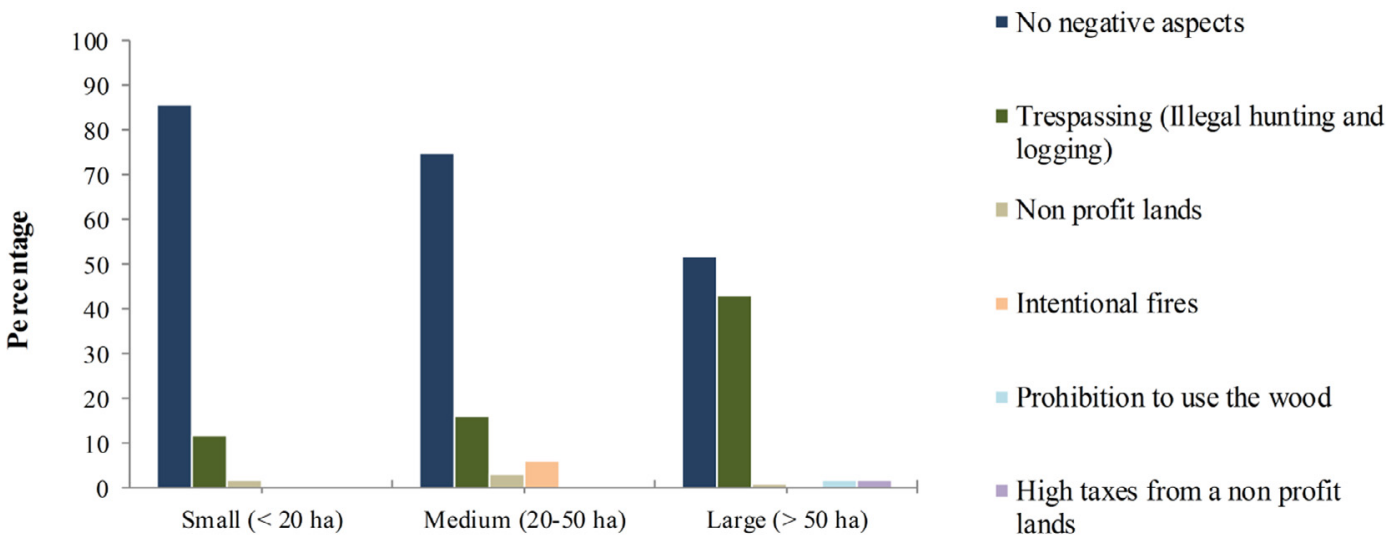

Farm Size

Fig. 7. Negative aspects of forest according to farm size.

dent on the forest. Medium-scale farmers, however, showed less dependence on forest resources (Fig. 8), although $77 \%$ stated that they still use these resources. Unlike the previous groups, $56 \%$ of large-scale farmers claimed that they did not use the forest, whereas the remaining $44 \%$ stated that they made some use of it, but not intensively.

Fig. 9 shows the types of uses for the forest, and about 93\% of small-scale farmers stated that they use the forest especially for collecting firewood. However, a decreasing trend is observed in the group of medium- and large-scale farmers, where the extraction of firewood is $55 \%$ and $28 \%$, respectively (Fig. 9). Similar tendencies were seen in the use of the forest for construction wood. While $83 \%$ of small-scale farmers used the forest as a source of wood for construction, this use is less frequent among mediumand large-scale farmers ( $45 \%$ and $19 \%$ of the respondents, respectively). Small land owners showed a high reliance on forest products, which can be attributed to the lack of sufficient income (Fig. 9). For example, as seen in Fig. 3A and B, most small households own houses built from wood extracted from the forest. Additionally, harvesting firewood appears to be required by small-scale farmers, and $90 \%$ of these farmers depend on firewood for subsis-

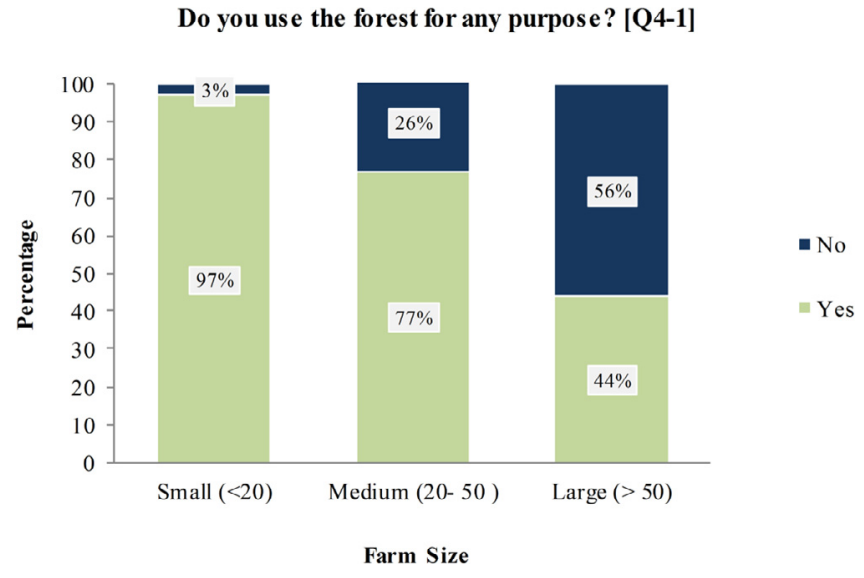

Fig. 8. Utilization of forest (yes/no) according to farm size.

tence proposes (cooking). In contrast, medium- and large-scale farmers do not rely as much on forest products; most of them live in permanent homes with access to electricity and gas. Although 


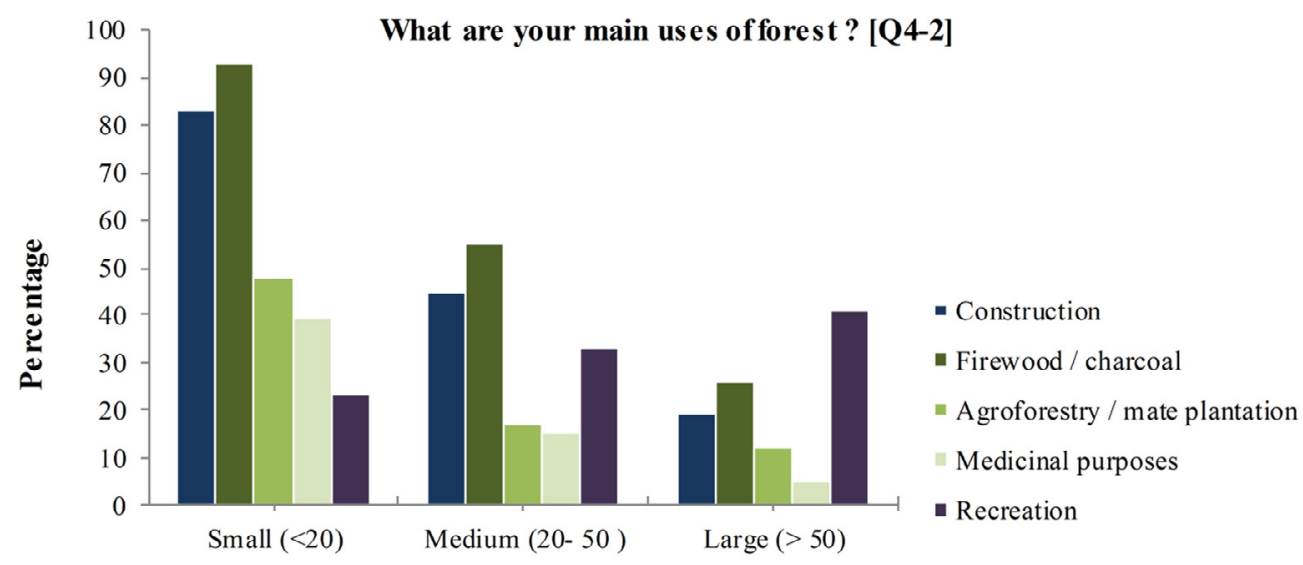

Farm size

Fig. 9. Main uses of the forest according to farm size.

they still harvest wood from the forest, they do so to produce wooden poles for fences or wooden barns for raising cattle. Unlike small-scale farmers, large land owners ( $41 \%$ in this category) considered the forest's main value to be recreational, while $12 \%$ acknowledged the agroforestry option, and only 5\% mentioned harvesting medicinal plants.

Fig. 9 shows that $48 \%$ and $39 \%$ of small landowners use the forest for forest farming and medicinal proposes, respectively. Most farmers engaging in forest farming (either large- or mediumscale farmers) do so for mate tea production as an additional source of income, while harvesting medicinal plants is mostly used for self-consumption. Farmers were further asked if they think that harvesting for construction or fuel was legal: $71 \%$ of respondents thought it was allowed; only $23 \%$ were fully aware that it was illegal and over $6 \%$ did not know.

This suggests that most of the harvesting that is being carried out happens with the (erroneous) understanding that it is permitted. Thus, $70 \%$ of the harvesting is being done by small-scale land owners, of whom $78 \%$ do not possess any knowledge of environmental regulations.

When asked how much more of their yearly income would have to be designated for firewood if the forest was not available, answers varied from $\$ 18-\$ 4,000$ USD, with an average of $\$ 476$ USD. For wood supplied for the purpose of construction, the esti- mated replacement cost if no free-of-charge resources were available fluctuated from $\$ 36-\$ 7,000$ USD (with a mean of $\$ 1,553$ USD). Taken together, this amount would be equivalent to $46 \%$ of the income of the annual rural wage (\$6,500 USD according to the DEGEEC 2002). Farmers were also asked how much forest-related products contribute to their annual earnings. Interviewees were able to choose between four categories: all of it, more than $50 \%$, between $50 \%$ and $30 \%$, or none of their household income could be attributed to the forest. Because the category "all of it" was not selected by any of the respondents, Fig. 10 only shows the remaining three categories. In general, $73 \%$ of the respondents stated that forest-related products do not contribute to their income. Fig. 10 shows that small-scale famers are the group with the highest dependency on the forest, with $40 \%$ of the respondents claiming that forest-related products contributed between $30 \%$ and $50 \%$ of their annual income. Most medium-scale farmers (22\%) had profits from the forest that were in the $30-50 \%$ range, because their earnings were principally from agroforestry practices and mate production. Additionally, Fig. 10 presents large-scale farmers (10\%) as the group that profits the most from the forest, claiming that the forest contributes to over $50 \%$ of their annual income. However, this trend may be because the respondents were in charge of protected areas where the economy is largely depended on tourism.

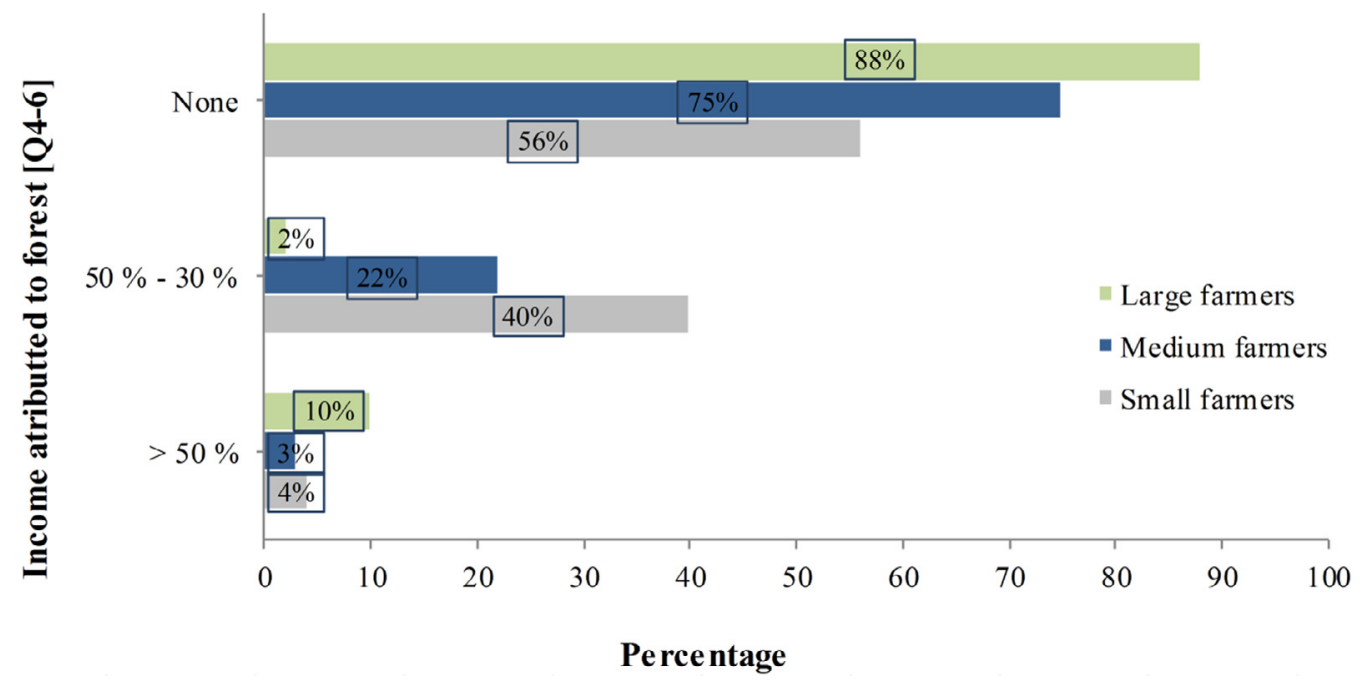

Fig. 10. Percentage of household income attributed to forest related productst according to farm size. 
Farmers were asked to estimate the worth of 1 ha full of forest. Interviewees could freely state a figure, without any ranges given. No clear pattern was seen among farm sizes. Answers ranged from $\$ 12,000-\$ 15,000$ USD, with an average of $\$ 13,671$ USD. Some farmers frequently stated that 1 ha full of forest would not be attractive to purchase at this time, because the current environmental regulations prohibit the transformation of forest land into land for other uses. Profits obtained from forest-related products cannot be compared to the ones from agricultural lands (soy bean production) in terms of revenue on the national/international market. When landowners were asked if they thought that cutting down forests would reduce their income, $75 \%$ of small-scale farmers agreed, whereas $56 \%$ and $74 \%$ of medium- and large-scale famers disagreed, respectively.

\subsection{Perception of forest protection and conservation programs}

To understand perceptions about preserving the BAAPA, farmers were asked if the natural forest should be protected. Overall, positive feedback was obtained, with $98 \%$ of the respondents showing their support for protecting natural areas. Landowners were further asked if they would consider reducing forest lands to increase agricultural productivity: over $84 \%$ disagreed by highlighting the importance of forests for their livelihoods. Additionally, $91 \%$ of farmers claimed that if the forest disappeared it would have a negative impact on the environment and associated natural resources, such as water reservoirs, and local fauna. Following the set of questions, farmers were further asked if they considered that it would be better if more trees were planted. Responses varied by owned land size (see Fig. 11).

Strong support towards reforestation was seen among smallscale (95\%) and medium-scale (78\%) farmers, but $48 \%$ of largescale farmers agreed, as long as their current agricultural crop lands would not be converted into forest. However, 29\% of the overall respondents indicated that reforestations could not take place because all their lands were covered by crops. Since the region was recently affected by extreme weather events, landowners were asked what the importance of preserving the forest to reduce erosion or for protection against storms meant to them. The majority of small-scale (86\%) and medium-scale (70\%) farmers agreed that a decrease in forest land on their property would increase the risk of erosion, while $59 \%$ of large-scale famers claimed that erosion can be controlled by "good agricultural practices", which are independent of the presence of forest. People were further asked if the forest provided any kind of protection for their crops. Generally, over 77\% of landowners believed that the forest serves as a barrier against soil erosion or that it reduces

Inclination to reforestation programs [Q12-1]

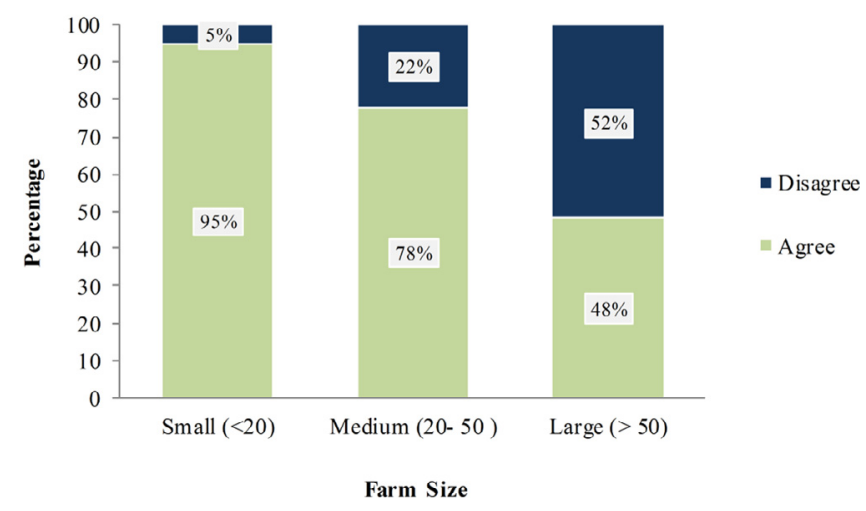

Fig. 11. Predisposition to reforestation programs according to farm size. the damage caused by intensive rain. However, there is a large group of landowners (23\%) who do not acknowledge the forest as a means of protection, particularly large-scale farmers (39\%). This trend is not surprising because for large scale soy production, forests are not considered to be relevant (according to the respondents), either to enhance the production itself or as a mean of protection against pests and diseases. People were also asked if they believe that extreme climate events were related to the disappearance of the forest. While the majority of small-scale (90\%) and medium-scale (69\%) farmers agreed, 68\% of large landowners did not agree. The respondents claimed that during the $1970 \mathrm{~s}$, similar events occurred in the region, when the area was still covered entirely by forest.

With regards to conservation programs, farmers were asked if they ever received information concerning the sustainable use of forest and natural resources. Overall, 60\% of respondents confirmed their involvement in workshops or programs, but largescale farmers had the highest attendance (67\%). When the respondents were asked about their main motivation, 56\% of the respondents selected "improve the environment" as their main motivation, 33\% stated that they wanted to "increase their income", and $11 \%$ indicated "to be alienated by current environmental regulations". Based on the results, farmers appear to be highly environmentally conscious. Moreover, $68 \%$ of the respondents indicated that to date, they are still using the information they acquired in the programs or workshops to protect water resources, agroforestry systems, and forest farming. People were asked about their knowledge of the PES and the possibility that they would use their forest lands in the program. During the interview, "understanding of the PES program" was acknowledged when respondents had some knowledge of the basic tenets of the program. The large-scale landowners group had a higher percentage of respondents (46\%) who were aware that the PES program existed compared with medium-scale (20\%) and small-scale (11\%) farmers. Fig. 12 shows the willingness of farmers to include their properties in the PES program. According to PES law, only properties with more than 20 ha must fulfill the regulations of the $422 / 73$ law (maintaining more than $25 \%$ of their property as natural forest) to benefit from the program. Small landowners ( $<20$ ha) are exempt from the 422/73 law. Thus, any remnant of natural forest can be considered for environmental credits as long as they conform to the requirements set by the Ministry of Environment of Paraguay (SEAM). As presented in Fig. 12, strong support for the program was shown among small-scale (91\%) and large-scale (80\%) farmers.

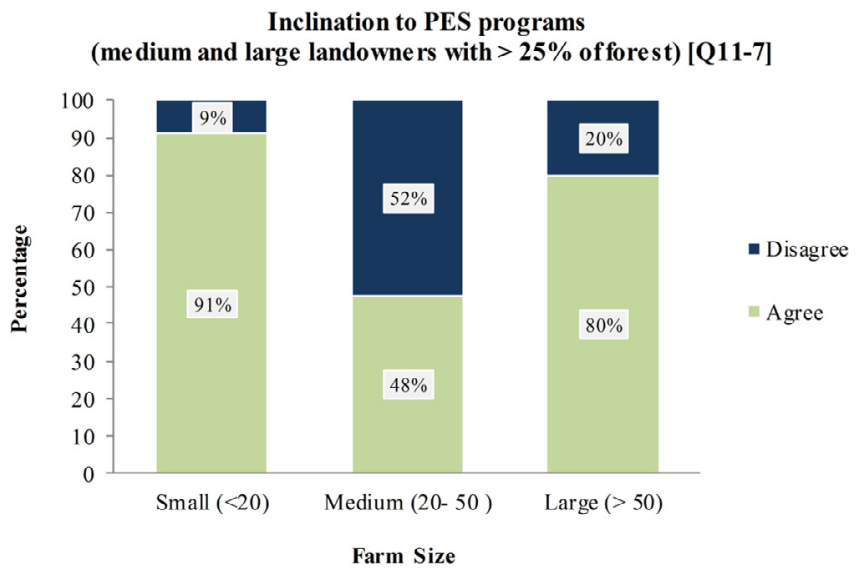

Fig. 12. Predisposition to PES programs according to farm size. 


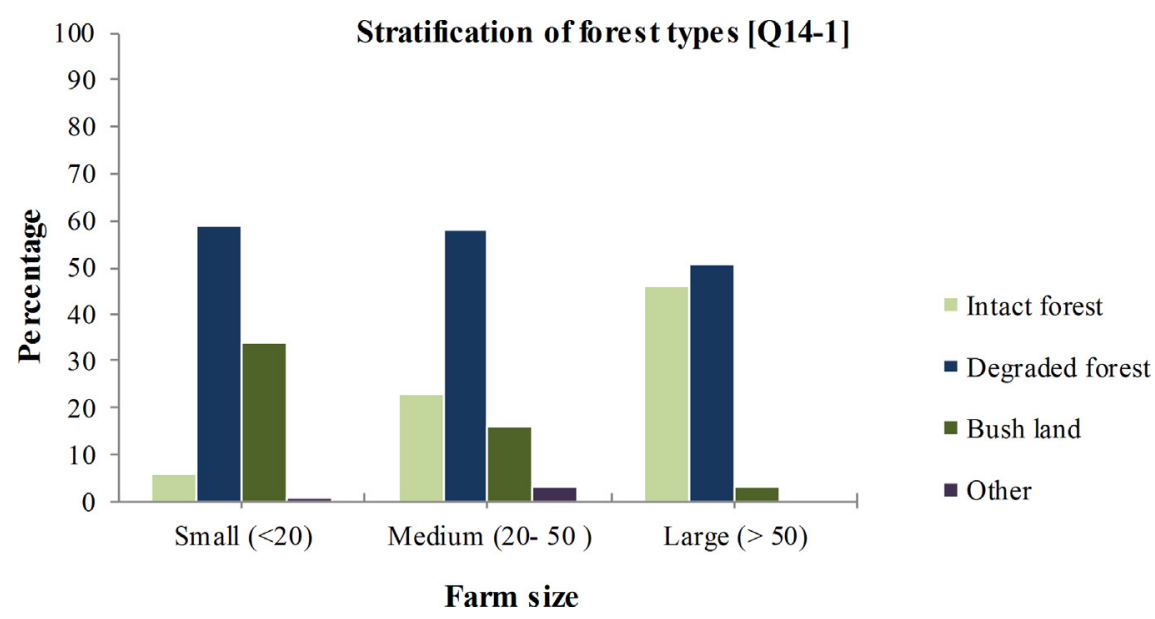

Fig. 13. (a)-(c) Stratification of forest type according to farm size (represented in percentages) [Q14-1].

\subsection{Perception of the general state of the forest and expected future trends}

Over the last part of the survey, the questions were intended to understand how farmers perceive the status of the forest and which notable challenges the BAAPA is likely to face in the future. When asked about the state of the BAAPA, 57\% of the respondents indicated that they lacked knowledge concerning the rapid disappearance of the eco-region.

Responses among different farmer groups were compared, and large-scale landowners (60\%) seemed to be more familiar with the current state of the BAAPA, whereas $77 \%$ of small-scale farmers lacked knowledge about the status of the overall eco-region. Additional questions were asked about environmental laws. Similar to the previous section, understanding of environmental regulations was defined as when respondents were aware of any of the current environmental laws in the country (e.g., afforestation and deforestation laws, water courses regulations, and penalties for breaching the environmental legislation). According to our analysis, medium-scale (80\%) and large-scale (96\%) farmers had a higher percentage of respondents with some knowledge of environmental laws compared with small-scale farmers (22.4\%). However, this trend could be because farmers who own more land (mediumscale and large-scale) are engaged in more activities related to environmental permissions and transactions as a result of the size of their property, which might be affected by new regulations and laws. When farmers were asked for their opinion on current environmental regulations, more than $80 \%$ of the respondents indicated their satisfaction with the existing legislation. However, farmers claimed that a high level of corruption was seen among national authorities who were responsible for law enforcement, which compromised the conservation of natural areas. People were also asked the state of their own forest and the future of the BAAPA. Fig. 13 presents the farmers' perception of the status of their own forest. The amount of forest left intact increased along with the size of the properties (Fig. 13). Degraded forest, however, seems to be the most common land category for all groups. Distinct from intact forest, bush lands appears to be more common on smaller farms and decreases as farm size becomes larger. Bush lands in the BAAPA region are commonly known as "capuerones", or lands covered by bamboo, bushes, and weeds, that has no economic value. All farmers groups referred to their forest as "degraded" when no valuable species of considerable height and diameter (over $10 \mathrm{~m}$ high and $30 \mathrm{~cm}$ of breast height (DBH)) were found on their land. Intact forest, however, was defined as a forest which has not been disturbed over the last decades and which had a high frequency of valuable tree species that still dominated the upper canopy.

Finally, when farmers were asked about the future of the BAAPA over the next 10 years, $61 \%$ of the respondents believed that the forest cover would continue to decrease.

\section{Discussion}

The value given to the forest and the services provided is a topic of significant importance, but it has not been well studied (Lamarque et al., 2011). If the objective is to implement successful environmental policies that are intended to lead to the sustainable use and conservation of natural resources, local users from the forest must be involved (Sodhi et al., 2009; Casado-Arzuaga et al., 2013). Therefore, their opinions, preferences, and tendency towards conservation initiatives must be understood (CasadoArzuaga et al., 2013). The present study focuses on understanding how the BAAPA's ecosystem services are being perceived by different farmers' groups and to determine the influence of these groups on forest conservation.

Throughout the present study, a social dependence on the services provided by the forest was observed. Farmers depend directly on the ecosystem for subsistence. However, their level of reliance varies according to farm size; less dependency was seen as farm size increased. For small-scale farmers, dependence on the forest is closely related to their income level. For example, a small-scale farmer who owns only 5 ha of land and is a government employee could earn up to $\$ 5,000$ USD per year (DGEEC, 2002) without exploiting the forest for subsistence purposes. However, a smallscale farmer with 18 ha of land and no other source of income can earn less than $\$ 1,000$ USD per year (DGEEC, 2002), thus depending heavily on the forest for subsistence. However, among the interviewees, few farmers had jobs in governmental institutions (e.g., professors, accountant assistant, nurses) or private companies (e.g., technical coordinators, salesman, and administrators). Similar results were observed in several studies such as Hartter (2010), Balvanera et al. (2012), Casado-Arzuaga et al. (2013), and Kuenzer and Tuan (2013), where reliance on the ecosystem differed with the source of income (major job type) and the type of ecosystem analyzed.

The survey identified three main categories of ecosystem services used by the respondents: provisioning services (collecting firewood, timber for construction, medicinal plants, and understory crops), cultural services (recreation), and regulatory services 
(erosion control and water cleansing) (Fig. 1) (Carpenter, 2005). Provisioning services appear to be more significant for smallscale and medium-scale farms, whereas cultural services are more important to large-scale landowners. The present trend appears logical because the income level among the different farmers' groups had a large variation, and thus, the reliance on forest resources for daily subsistence also differed. For example, whereas firewood and timber are essential for food and shelter among small-scale farmers, forest goods for medium-scale and largescale farmers would be better described as an additional source of income. Large-scale farmers used forest resources much more sparingly than did the other classes of farmers. However, this restraint in resource use is related to the constant pressure exerted on the farmers by environmental authorities. Large-scale farmers perceive that they are constantly been pursued by local authorities who demand payment in exchange for permission to use the forest, whereas small-scale farmers are allowed to use the forest without restriction. However, according to forest law 542 article 25, "all landowners (no exception concerning farm size) who want to benefit from the forest must obtain a permit issued by the SEAM" (MAG, 2002).

The forest's regulatory services seem to be more important to small-scale and medium-scale farmers, especially for erosion control and water retention. Large scale-farmers, however, do not see the relevance of the forest to these services, stating that soil conservation can be achieved equally well by implementing good agricultural practices (e.g., direct seeding system). An additional service, primarily identified by small-scale farmers, consists of the ability of the forest to provide the necessary ecological conditions for forest farming (mate production mostly). Despite this farming practice being common only among small-scale farmers, forest farming was shown to be profitable when diversification of the production is needed to generate additional income (Montagnini et al., 2011). For cultural services, large-scale farmers use the forest primarily for recreational purposes, which could be related to their fear of environmental authorities penalizing them for other uses (as described above).

Overall trends in the percentage of income obtained from forest resources indicate that forest products mostly do not contribute to the annual household income. The observed trend is consistent with the large majority of farmers who consider forest products to be insufficient (in monetary terms) to secure their subsistence livelihoods. Especially for small-scale farmers, this tendency can be attributed to their lack of proper land management. Thus, natural resources have been degraded to the point where only a few products can be obtained, which are used solely for selfsufficiency. Additionally, small-scale farmers tend to lease their properties (between $\$ 700$ and $\$ 800$ USD per ha per year (according to the interviewees)) to large soybean producers, leaving only a small share of land for their own crops. Depending on the global market and production (per ha per year), a soy bean producer can earn up to $\$ 2,100$ USD per ha per year (MAG, 2008). Unlike soy crops, forest products (from natural areas) in the country do not have a stable market, which hinders proper commercialization of the products (according to the respondents). When farmers were asked how much 1 ha full of forest was worth, figures given by the respondents were according to actual price of the land itself in the region (based on the National Service of Cadastral Data from Paraguay (SNC)), independent of the percentage of forest cover on their property. Currently, most of the interviewees perceive that 1 ha of soy crops holds a higher economic value than 1 ha of natural forest.

All farmers' groups (especially small-scale farmers) showed a strong interest in for the PES 3001/06 law, even though their knowledge of the details of the program was limited. Study cases from Brazil and Costa Rica demonstrated that, at least for small land owners, PES programs presented positive results to alleviate poverty (Wunder et al., 2008). However, to date, only a few landowners have registered their forest lands, citing the many regulations and large amount of paperwork involved in obtaining the required certificate. Similar constraints were found in Costa Rica and Mexico by Porras et al. (2013) and WWF (2015b), who showed that administrative issues discourage the inclusion of properties in the PES program. However, many respondents mentioned that all natural resources should be preserved because ecological resources must be protected, and therefore, there was no need to compensate the stakeholder for following the law. The same group of respondents referred to the PES program as being unfair; for them, every farm should contribute their share for the well-being of the environment and not just acquire certificates to be in compliance with the law. On the other hand, a small amount of farmers considered that payments established for 1 ha of forest in the region is not sufficient. The cost of protecting the forest itself (e.g., construction of fences, monitor the area, administrative cost to acquire the certificates) is much higher than the annual payments fixed by the PES program. Comparable outcomes were obtained from studies conducted in Brazil (Eloy et al., 2012; Wunder et al., 2008) where the cost opportunity of the land was compared with the low economic return from PES (Eloy et al., 2012 and Wunder et al., 2008). In general, better promotion of PES among farmers is needed, with a special focus on farmers with environmental liabilities (possible buyers) and farmers with large portions of forest cover (certificate owners). Moreover, the bureaucratic process and all administrative issues have to be simplified to increase the appeal for forest owners to participate.

Results of the survey also revealed a high level of environmental awareness among the respondents. Some properties (large-scale soybean producers) maintained forest reserves up to 300 ha beyond the area required by the law ( $>25 \%$ of the land), without receiving any kind of compensation. However, a higher percentage of farmers with environmental liabilities (lack of riparian forest or necessary forest cover) were observed on site. Several stakeholders stated that restoring the forest on their property was difficult, because most of their lands were already cultivated; to them, the forest represented a restriction to the expansion of agricultural areas. Additionally, misconceptions about forest laws were observed. For example, according to the forest law (422/73), a $25 \%$ forest cover is required for properties larger than 20 ha (without considering riparian forest), and several stakeholders counted the forest along the riverbanks in their total. This results in an overestimation of the percentage of natural forest area on their land, which leads to a disagreement with the environmental authorities about when reforestations activities should be conducted to fulfill the environmental regulations. Although the results showed stakeholder compliance with existing environmental laws, these laws, such as the 4241 law (riparian forest buffer) and the 542 law (forest resources), were not fully understood (MAG, 2002).

In the last part of the survey, farmers were asked about the future of the forest. A belief common to all stakeholders was that forest cover in the BAAPA would decrease over the next 10 years. The following statement is consistent with studies such as Hansen et al. (2013) and Da Ponte et al. (2015, 2016), which showed that the loss of forest cover in the BAAPA continues even when deforestation laws are in place. The level of corruption among environmental authorities was mentioned by all farmers' groups as the main factor obstructing forest preservation. In addition, a strong conflict of interest between farmers' groups was observed during the survey. Whereas small-scale farmers blame the large-scale farmers for cutting down the forest to expand their monoculture, large stakeholders blame small-scale farmers for trespassing, setting fire to their forests, illegal logging, and hunting. However, during the survey, few large-scale farmers admitted their 
previous mistake of cutting down the forest, defending themselves by saying that "they did not know the harm they were doing to the environment".

The responses derived from the survey might have some bias. First, the ministry of environment in Paraguay is currently concentrating its efforts on establishing a stronger enforcement of environmental laws in rural areas. Therefore, large-scale farmers might more conservatively answer questions about the condition of their forest, the use of forest resources, and general perceptions, to discourage further legal action by the government. The diversity of the interviewer's background could also have affected the responses in the survey, particularly within the group of farmers interviewed by WWF technicians. The constant pressure exerted by NGOs toward the enforcement of environmental regulations and conservation of natural resources, might have misled the true nature of the survey itself. Thus, WWF technicians could not have been perceived as neutral entities, which may have caused some bias in the responses. Finally, the distribution of the samples was affected by extreme weather events, making it difficult to access properties and properly cover the study areas. Thus, Fig. 2 shows a clustering of the samples especially within the Tavapy district and the districts that are within the Ñacunday watershed.

\section{Conclusions}

The goal of this study was to provide a comprehensive analysis of the perception and the value given by local landowners to the BAAPA's ecosystem services. Interviews were conducted individually with the designated representatives of 277 households distributed randomly among the ITAIPU and Nacunday watersheds and the Tavapy district, including the departments of Alto Parana and Canindeyú. The total study area covered 1,250,000 ha and included 42,490 households with 279,328 inhabitants. The forest provides a variety of supplies such as firewood, timber, ecologic conditions for forest farming, medicinal plants, erosion control, and recreational areas. However, because of the rapid expansion of large mechanized agriculture, forest lands in the BAAPA region have been disappearing rapidly. In a socio-economic survey undertaken in January 2016, a variety of topics were covered regarding farm size, income, education, the perception of the forest, the use of natural resources, and environmental awareness.

The mean household income greatly differed according to farm size. In general, $79 \%$ of farmers used the forest for a variety of purposes. Moreover, the use of forest for firewood and timber plays an important role for the farmers. From the people interviewed, 52\% used the forest for firewood or construction, without taking into consideration the current forest legislation. However, the extraction of wood has not been made completely illegal. Larger-scale farmers indicated their disagreement with the current local authorities, claiming that, unlike small-scale farmers, local authorities harassed them when they used the forest. Wood-related products from the BAAPA add up to an average of \$6,500 USD per year (46\% of the annual rural wage) that farmers would have to spend if the forest was unavailable. However, according to $73 \%$ of farmers, forest products do not contribute to their annual net income. Among the farmers, small landowners presented the highest dependency on the forest, with $40 \%$ of respondents claiming that forest goods contributed up to $50 \%$ their annual income.

The household survey showed the correlation between the importance of the forest and farm size. Whereas small-scale farmers see the forest as an essential source of goods for subsistence, medium- and large-scale farmers placed more importance on its cultural and recreational services. In general, $84 \%$ of the respondents considered the forest to be important for their livelihood and $91 \%$ claimed that if all the forest were logged, it would have a big impact on the environment. It can be concluded that farmers understand the importance of the forest as a functional ecosystem that offers a variety of services and plays a significant role on the equilibrium of the environment. However, products obtained from natural forests are not seen as a profitable source of income. Soy bean production still remains the most lucrative activity in the region.

Fifty-two percent of large-scale farmers felt skeptical of restoration programs because these programs could interfere with their former crops. PES programs were seen as a suitable alternative for almost $73 \%$ of the respondents, either as a way to purchase certificates or to register their lands. Farmers who did not agree with the PES program (27\%) frequently mentioned the lack of environmental responsibility from other farmers or neighbors, who were only interested in solving their environmental liabilities by purchasing environmental certificates. Thus, PES still requires further promotion (so that farmers have a better understanding of the concept) and a streamlined administrative processes to facilitate the procurement of environmental certificates. Establishment of pilot farms demonstrating successful cases of the program could increase forest owners' interest. Additionally, stratification of the payment levels should be considered, based on the type and quantity of services provided. Although the value of the PES certificates in Paraguay varies according to the relevance of the ecoregion, further environmental criteria would offer valuable assets for farmers to increase the remuneration from PES.

Generally, over $70 \%$ of farmers possessed degraded forest or bush land. Large-scale farmers held the largest remnants of intact forest, mostly because they applied the "Zero Deforestation Law" $(2524 / 04)$. In general, $61 \%$ of the farmers indicated that the forest cover would decrease over the coming 10 years, mainly because of weak law enforcement and corruption among the environmental authorities.

The results of this questionnaire provided insight into the differences in perception and usage of the forest among the distinct farmers' groups. Further studies could analyze the obtained information from the field in combination with remote sensing data. Responses could be validated by studying the dynamics of the forest cover from the farms visited (based on cadastral data) in combination with answers on perception and uses of forest services. Further decision-making for management of natural resources based on ES should consider the outlook of the rural population, and also strive to satisfy the needs of the different occupational groups in the region. Targeting priority areas for conservation and landowners who are likely to include their lands in environmental programs could ensure that conservation program goals are achieved over time.

\section{Acknowledgements}

This work was conducted under the Paraguay Land Use (PARLU) 'Protecting Forest for the.

Benefit of Climate, People and Nature in Paraguay' executed by WWF Paraguay and supported by the German Federal Ministry of Education and Research (BMBF). We would like to thank the volunteers from the career of Forestry from the National University of Asuncion and field technicians from WWF Paraguay for their support with the socio -economic household surveys.

\section{References}

Alegría, P., 2012. Guía para negociar mecanismos de retribución por servicios ecosistémicos con comunidades nativas. Fondo de las Américas del Peru (FONDAM), Lima, Peru.

Balvanera, P., Matos, D.M.S., Romero, L.P., Little, C., Gardner, T., Hall, J., Lara, A Laterra, P., Pen, M., Matos, D.M.S., Vogl, A.L., Romero-duque, L.P., Felipe, L., Oliveira, R.De., Ascarrunz, N., Correa, F., Cunha-santino, M.B., Herna, A.P., 2012. 
Ecosystem services research in Latin America: the state of the art. Ecosyst. Serv. http://dx.doi.org/10.1016/j.ecoser.2012.09.006.

Bennet, K., Henninger, N. 2009. Payments for Ecosystem Services in Costa Rica and Forest Law No. 7575: Key Lessons for Legislators. World Resources Institute.

Bitetti, M.S., Placci, G., Dietz, L.A., 2003. Biodiversity vision for the upper Paraná Atlantic forest ecoregion: designing a Biodiversity Conservation Landscape and Setting Priorities for Conservation Action. 1, 1-28. Washington, D.C.

Carpenter, S., 2005. Millennium ecosystem assessment. Science 314, 257-258.

Casado-arzuaga, I., Madariaga, I., Onaindia, M., 2013. Perception, demand and user contribution to ecosystem services in the Bilbao Metropolitan Greenbelt. J. Environ. Manage. 129, 33-43. http://dx.doi.org/10.1016/j.jenvman.2013.05.059.

Costanza, R., 2000. Social goals and the valuation of ecosystem services. Ecosystems 3 (1), 4-10. http://dx.doi.org/10.1007/s100210000002.

Da Ponte, E., Fleckenstein, M., Leinenkugel, P., Parker, A., Oppelt, N., Kuenzer, C., 2015. Tropical forest cover dynamics for Latin America using Earth observation data: a review covering the continental, regional, and local scale. Int. J. Remote Sens. 36 (12), 3196-3242. http://dx.doi.org/10.1080/01431161.2015.1058539.

Da Ponte, E., Roch, M., Leinenkugel, P., Dech, S., Kuenzer, C., 2016. Paraguay's Atlantic Forest cover loss- Satellite - based change detection and fragmentation analysis between 2003 and 2013. Appl. Geogr. 79, 37-49. http://dx.doi.org/ 10.1016/j.apgeog.2016.12.005.

Daily, G., 1997. Nature's Services: Societal Dependence on Natural Ecosystems. Island Press, Washington, DC.

DGEEC, 2002. Direccion General de Estadistica, Encuestas y Censos. Atlas censal del Paraguay, Asuncion - Paraguay. http://www.dgeec.gov.py/.

Eloy, L., Meral, P., Ludewigs, T., Tosello, G., Singer, B., 2012. Payments for ecosystem services in Amazonia. The challenge of land use heterogeneity in agricultural frontiers near Cruzeiro do Sul (Acre, Brazil). J. Environ. Planning Manage. 11, 685-703. http://dx.doi.org/10.1080/09640568.2011.621021.

FAO (Food and Agriculture Organization), 2007. Manual on Deforestation, Degradation, and Fragmentation Using Remote Sensing and GIS. Rome.

FAO (Food and Agriculture Organization), 2010. Global Forest Resources Assessment 2010. Main report. FAO Forestry Paper 163. For. Pap. 163, 350 pp. doi:ISBN 978-92-5-106654-6.

FAO (Food and Agriculture Organization), 2015. Global Forest Resources Assessment 2015, Desk Reference.

Fleytas, C., 2007. Cambios en el paisaje. Evolución de la cobertura vegetal en la Región Oriental del Paraguay, Asuncion - Paraguay.

Grima, N., Singh, S.J., Smetschka, B., Ringhofer, L., 2016. Payment for Ecosystem Services (PES) in Latin America: analysing the performance of 40 case studies. Ecosyst. Serv. 17, 24-32. http://dx.doi.org/10.1016/j.ecoser.2015.11.010.

Hansen, M.C., Stehman, S.V., Potapov, P.V., 2010. Quantification of global gross forest cover loss. Proc. Natl. Acad. Sci. U. S. A. 107, 8650-8655. http://dx.doi.org/ $10.1073 /$ pnas.0912668107.

Hansen, M.C., Potapov, P.V., Moore, R., Hancher, M., Turubanova, S.A., Tyukavina, A., Thau, D., Stehman, S.V., Goetz, S.J., Loveland, T.R., Kommareddy, A., Egorov, A., Chini, L., Justice, C.O., Townshend, J.R.G., 2013. High-Resolution Global Maps of 21st-Century Forest Cover Change. Science 342 (80), 850-853. http://dx.doi. org/10.1126/science.1244693.

Hartter, J., 2010. Resource use and ecosystem services in a Forest Park Landscap. Soc. Nat. Resour. An Int. J. 23, 207-223. Preview Full text DOI:10.1080/ 08941920903360372.

Hein, L., van Koppen, K., de Groot, R.S., van Ierland, E.C., 2006. Spatial scales, stakeholders and the valuation of ecosystem services. Ecol. Econ. 57, 209-228. http://dx.doi.org/10.1016/j.ecolecon.2005.04.005.

Huang, C., Kim, S., Altstatt, A., Townshend, J.R.G., Davis, P., Song, K., Tucker, C.J., Rodas, O., Yanosky, A., Clay, R., Musinsky, J., 2007. Rapid loss of Paraguay's Atlantic forest and the status of protected areas - a Landsat assessment. Remote Sens. Environ. 106, 460-466. http://dx.doi.org/10.1016/j.rse.2006.09.016.

Huang, C., Kim, S., Song, K., Townshend, J.R.G., Davis, P., Altstatt, A., Rodas, O., Yanosky, A., Clay, R., Tucker, C.J., Musinsky, J., 2009. Assessment of Paraguay's forest cover change using Landsat observations. Glob. Planet. Change 67, 1-12. http://dx.doi.org/10.1016/j.gloplacha.2008.12.009.

Hutchison, S., Aquino, L., 2011. Making a pact to tackle deforestation in paraguay 118.
Israel, G., 1992. Determining sample size, program evaluation and organizational development. Inst. Food Agric. 5.

Kernan, B.S., Cordero, W., Macedo Sienra, A.M., Marín, J.V., 2010. Report on Biodiversity and Tropical Forests in Paraguay.

Kuenzer, C., Tuan, V.Q., 2013. Assessing the ecosystem services value of can gio mangrove biosphere reserve: combining earth-observation- and householdsurvey-based analyses. Appl. Geogr. 45, 167-184. http://dx.doi.org/10.1016/j. apgeog.2013.08.012.

Lamarque, P., Tappeiner, U., Turner, C., Steinbacher, M., Bardgett, R.D., Szukics, U., Schermer, M., Lavorel, S., 2011. Stakeholder perceptions of grassland ecosystem services in relation to knowledge on soil fertility and biodiversity. Reg. Environ. Chang. 11, 791-804. http://dx.doi.org/10.1007/s10113-011-0214-0.

MAG (Ministerio de Agricultura y Ganaderia. Informer sector Agropecuario), 2002. LEY N ${ }^{\circ}$ 1.863/02 [WWW Document]. URL http://www.mag.gov.py/Ley 1863-02. pdf (accessed 7.6.16).

MAG (Ministerio de Agricultura y Ganaderia. Informer sector Agropecuario), 2008 ISA. Asuncion - Paraguay.

Markey, B., 2014. USDA GAIN Report. Global Agricultural information Network. Oilseeds and Products Annual, Paraguay, p. 8.

Mayers, N., 1988. Threatened biotas: "Hot spots" in tropical forests. Environmentalist 8.

MEA (Millennium Ecosystem Assessment), 2005. Ecosystems and Human WellBeing: Biodiversity Synthesis. World Resources Institute, Washington, DC.

Mittermeier, R.A., Myers, N., Mittermeier, C.G., 1999. Hotspots: Earth's biologically richest and most endangered terrestrial ecoregions. CEMEX and. ed Washington, DC.

Montagnini, F., Eibl, B.I., Barth, S.R., 2011. Organic yerba mate: an environmentally, socially and financially suitable agroforestry system. Bois. Foret. Des. Trop. 308 59-74.

Myers, N., Mittermeier, R.A., Mittermeier, C.G., da Fonseca, G.A., Kent, J., 2000. Biodiversity hotspots for conservation priorities. Nature 403, 853-858. http:// dx.doi.org/10.1038/35002501.

Natural Earth, 2014. Free Vector and Raster Map Data [WWW Document].

Oak Ridge National Laboratory, 2013. Landscan 2002 and 2010. [WWW Document].

Olson, D.M., Dinerstein, E., 2002. The Global 200: priority Ecoregions for Global Conservation. Ann. Missouri Bot. Gard. 89, 199-224. http://dx.doi.org/10.2307/ 3298564.

PNUD (Programa de las Naciones Unidas para el Desarrollo), 2010. Sector rural paraguayo: una vision general para un dialogo informado. Asuncion - Paraguay.

Porras, I., Barton, D.N., Miranda, M. Chacón-Cascante, A. 2013. Learning from 20 years of Payments for Ecosystem Services in Costa Rica. International Institute for Environment and Development. ISBN:9781843698555.

SEAM (Secretaria del Ambiente), 2016. Listado de Áreas Certificadas [WWW Document]. URL http://www.seam.gov.py/servicios/servicios-ambientales/ listado-de-\%C3\%A1 reas-certificadas (accessed 7.10.16).

Sodhi, N.S., Lee, T.M., Sekercioglu, C.H., Webb, E.L., Prawiradilaga, D.M., Lohman, D.J., Pierce, N.E., Diesmos, A.C., Rao, M., Ehrlich, P.R., 2009. Local people value environmental services provided by forested parks. Biodivers. Conserv. 19, 1175-1188. http://dx.doi.org/10.1007/s10531-009-9745-9.

Stern, M. and Kernan, S.B., 2011. Report on Biodiversity and Tropical Forests in Ecuador, Usaid.Ba0.Biz.

UN-REDD, 2010. National Programme Document - Paraguay. UN-REDD Programme Policy Board Meeting, Washington D.C.

Wunder, S., Engel, S., Pagiola, S., 2008. Taking stock: a comparative analysis of payments for environmental services programs in developed and developing countries. Ecol. Econ. 65, 834-852. http://dx.doi.org/10.1016/j. ecolecon.2008.03.010.

WWF (World Wildlife Fund), 2013. Paraguay extends Zero Deforestation Law to 2018. WWF report.

WWF (World Wildlife Fund), 2015a. Conceptos de Proyectos Piloto. Paraguay Land Use -ParLu, Asuncion Paraguay.

WWF (World Wildlife Fund), 2015b. Payments for Ecosystem Services: background Information and Evaluation of case studies. WWF report, Germany, Berlin.

Yamane, T., 1967. Statistics: an Introductory Analysis. Harper and Row, New York. 